\title{
Production of Carbon Nanotubes and Hydrogen Catalyzed with Ni/MCM-41 Catalysts
}

\author{
Zhiqi Wang ${ }^{*}$, Juan Navarrete ${ }^{2}$ \\ ${ }^{1}$ The American School Foundation, Mexico City, Mexico \\ ${ }^{2}$ Dirección de Investigación y Posgrado, Instituto Mexicano del Petróleo, Mexico City, Mexico \\ Email: *wang_extreme@hotmail.com
}

Received March 27, 2012; revised April 28, 2012; accepted May 21, 2012

\begin{abstract}
Methane catalytic decomposition (MCD) over Ni/MCM-41 catalysts was tested in a microreactor to simultaneously produce hydrogen and carbon nanotubes (CNTs). The methane conversion reached $30 \%$ to $47 \%$ at a moderate temperature range from $400^{\circ} \mathrm{C}$ to $600^{\circ} \mathrm{C}$ and the catalytic activity of the catalysts remains stable during 500 min steam on time. CNTs were chiefly formed through tip-growth mode, due to the weak interaction between the metallic Ni and the support. Most of the Ni particles are located on the tip of the produced CNTs, which avoids rapid deactivation of the catalyst resulted from carbon encapsulation. Large Ni particles usually lead to the formation of CNTs with big diameter. During the reaction, the shape of Ni particles changed from pseudo-sphere to diamond-like. All the CNTs consist of multiple layer walls and are curved in certain degree.
\end{abstract}

Keywords: Methane Catalytic Decomposition; Hydrogen, Carbon Nanotubes; Catalysts; Ni/MCM-41

\section{Introduction}

Currently, a great attention has been paid to the use of hydrogen on a very large scale in chemicals, food and petroleum refining industries, fuel cell technology, space exploration and other fields. Hydrogen as a fuel has several advantages: it is widely available, easy to handle and has the largest heating coefficient among fuels; more important is that, water is the sole product of hydrogen combustion; therefore, it is an environmentally friendly fuels $[1,2]$.

Several techniques have been developed for hydrogen production including: steam reforming, biomass gasification, and water electrolysis etc. [3]. In the steam reforming of hydrocarbons, one of the products, $\mathrm{CO}$, has to be removed by subsequent steps because it strongly poisons the Pt-catalyst which is the key of fuel cell technology. This significantly increases the production cost. Electrolysis of water may offer clean hydrogen without $\mathrm{CO}$; however, it is too expensive as a result of electricity utilization. One of the most promising routes for hydrogen production is the direct decomposition of methane, which has the highest hydrogen to carbon ratio in comparison with other hydrocarbon compounds. Through this approach, formation of $\mathrm{CO}$ can be avoided; thus, the subsequent steps for removal of $\mathrm{CO}$ are not necessary.

${ }^{*}$ Corresponding author.
This route is believed to be superior to both electrolysis of water and steam reforming from the economical point of view $[3,4]$.

On the other hand, carbon nanotubes have also attracted great attention for a long time due to their excellent properties and potential utilization in a variety of nanotechnologies $[5,6]$. One technique used to produce CNTs is the catalytic growth of carbon atoms from decomposition of hydrocarbons. In the methane catalytic decomposition (MCD), if the production of both hydrogen and carbon nanotubes can be effectively combined, we may simultaneously obtain $\mathrm{CO}$-free hydrogen and CNTs by using the same reaction.

The most commonly catalysts used for MCD are the transition metals group VIII ( $\mathrm{Co}, \mathrm{Ni}$ or $\mathrm{Fe}$ ) supported on oxides like $\mathrm{Al}_{2} \mathrm{O}_{3}$ and $\mathrm{SiO}_{2}$. Rahammad and coworkers report that the MCD reaction over a $5 \mathrm{wt} \% \mathrm{Ni} / \gamma-\mathrm{Al}_{2} \mathrm{O}_{3}$ showed a high activity between $500^{\circ} \mathrm{C}$ and $550^{\circ} \mathrm{C}$ in a thermal balance evaluation system [7]. The catalyst exhibited high activity at $500^{\circ} \mathrm{C}$ in fifteen hours of reaction. It was rapidly deactivated within $2-3 \mathrm{hrs}$ above $600^{\circ} \mathrm{C}$ due to the deposition of carbon materials. Carbon formation was also investigated in the MDC over bare $\alpha$-Fe and with $\mathrm{Fe} / \mathrm{Al}_{2} \mathrm{O}_{3}, \mathrm{Fe} / \mathrm{ZrO}_{2}, \mathrm{Fe} / \mathrm{SiO}_{2}$ and $\mathrm{Fe} / \mathrm{TiO}_{2}$ catalysts at temperatures between $400^{\circ} \mathrm{C}$ and $600^{\circ} \mathrm{C}$ [8]. Under the same reaction condition, $13.5 \mathrm{~g}, 14 \mathrm{~g}, 17.4 \mathrm{~g}$ and $45 \mathrm{~g}$ carbon were yielded over the $\mathrm{ZrO}_{2}, \mathrm{Al}_{2} \mathrm{O}_{3}, \mathrm{TiO}_{2}$ and $\mathrm{SiO}_{2}$ supported $\mathrm{Fe}$ catalysts, respectively. This work 
clearly shows that catalyst support greatly impacts on the catalytic activity and carbon production.

It is noteworthy that mesoporous materials like MCM41 and SBA-15 were frequently used as catalyst support due to their great surface area $\left(>800 \mathrm{~m}^{2} / \mathrm{g}\right)$, large pore volume $\left(>0.5 \mathrm{~cm}^{3} / \mathrm{g}\right)$ and ordered pore system [9-11]. Investigating of the catalyst with new support like mesoporous MCM-41 for simultaneous production of COfree hydrogen and CNTs will be an interesting research task.

In the present work, Ni/MCM-41 catalysts was used for simultaneous production of $\mathrm{CO}$-free hydrogen and CNTs and its catalytic activity and stability were tested in a microreactor using methane as reaction feedstock. Carbon nanotube formation, including its wall thickness, length, diameter and shape was discussed.

\section{Experimental}

\subsection{MCM-41 Synthesis}

For MCM-41 synthesis, fumed silica was used as $\mathrm{Si}$ source and cetyltrimethylammonium chloride $(\mathrm{CTACl})$ as synthetic template. $1.2 \mathrm{~g}$ of fumed silica were added into $10.0 \mathrm{~g}$ of $45 \%$ tetrabutylammonium hydroxide (TBAOH) aqueous solution while vigorously stirring for $30 \mathrm{~min}$ to form a transparent gel. Then, $30 \mathrm{~g}$ of cetyltrimethylammonium chloride $(25 \mathrm{wt} \%$ solution in water) were added into the above gel during agitation. The gel was thermally aged at $80^{\circ} \mathrm{C}$ for $72 \mathrm{~h}$; afterwards, the mixture was filtered and washed 3 times using $500 \mathrm{ml}$ deionized water, and the resultant solid was dried at ambient temperature for $12 \mathrm{hrs}$. It was then calcined at $600^{\circ} \mathrm{C}$ for $6 \mathrm{hrs}$ under an air flow condition (air flow rate was $60 \mathrm{ml} / \mathrm{min}$ ). In the calcination procedure, care was taken by increasing the temperature with a rate $1^{\circ} \mathrm{C} / \mathrm{min}$, in order to avoid mesostructure collapsing of the sample. All the chemicals used in this work were supplied by Sigma Chemical Co. Ltd.

\subsection{Preparation of $\mathrm{Ni} / \mathrm{MCM}-41$ Catalysts}

The Ni/MCM-41 catalysts were prepared by impregnating MCM-41 support with $\mathrm{Ni}\left(\mathrm{NO}_{3}\right)_{2}$ solution. The $\mathrm{Ni}$ loading of the catalysts was $10 \mathrm{wt} \%, 20 \mathrm{wt} \%$ and $30 \mathrm{wt} \%$, respectively. After impregnation, the Ni supported MCM41 samples were dried at $70^{\circ} \mathrm{C}$ for $10 \mathrm{~h}$ and then calcined at $600^{\circ} \mathrm{C}$ for $4 \mathrm{~h}$. Before the catalytic evaluation, the catalyst samples were reduced using $99.9 \% \mathrm{H}_{2}$ at $500^{\circ} \mathrm{C}$ for $2 \mathrm{~h}$ with a flow rate of $30 \mathrm{ml} / \mathrm{min}$ to obtain metallic $\mathrm{Ni}$ particles on the catalyst.

\subsection{Characterization of the Materials}

The crystalline structures of the catalyst samples were analyzed with X-ray diffraction technique in a PANa- lytical difractometer (Model: X'Pert PRD) with a monochromatic $\mathrm{CuK} \alpha_{1}$ radiation $(\lambda=1.5400 \AA)$. The evaluation of the diffractograms was made by DIFFRAC/AT software. The scanning was made from $30^{\circ}$ to $100^{\circ}$, with a $2 \theta$ step size of $0.01^{\circ}$ and a step time of $2 \mathrm{~s}$.

The Raman spectrum was obtained at room temperature using a LabRam HR 800 spectrometer, equipped with a CCD detector. A laser diode of He-Ne system supplies a $633 \mathrm{~nm}$ exciting line and spectral resolution of $4 \mathrm{~cm}^{-1}$.

Transmission electron microscopy (TEM) observations were carried out in a JEM-2200FS transmission electron microscope with accelerating voltage of $200 \mathrm{kV}$. The microscope was equipped with a Schottky-type field emission gun and an ultra-high-resolution (UHR) configuration $(\mathrm{Cs}=0.5 \mathrm{~mm}$; $\mathrm{Cc}=1.1 \mathrm{~mm}$; point-to-point resolution, $0.19 \mathrm{~nm}$ ) and an omega-type in-column energy filter. The powder samples were grounded softly in an agate mortar and dispersed in isopropyl alcohol in an ultrasonic bath for several minutes. A few drops were then deposited on 200 mesh copper grids covered with a carbon film.

\subsection{Catalytic Evaluation}

The MCD reaction was carried out in a microreactor system (Advanced Scientific Design-RXM-100) with a stainless steel fixed bed reactor $(10 \mathrm{~mm}$ i.d. and $500 \mathrm{~mm}$ in length) at atmospheric pressure. The reaction temperatures varied from $400^{\circ} \mathrm{C}$ to $600^{\circ} \mathrm{C}$. The catalyst loading was ca. $150 \mathrm{mg}$. The inlet mixture was methane diluted in argon. The total inlet flow of the reaction gases was $75 \mathrm{ml} / \mathrm{min}$ ( $6 \mathrm{ml}$ of methane and $69 \mathrm{ml}$ of Ar). The rate of methane fed to the reactor was $2.67 \mathrm{mmol} / \mathrm{min}$. The temperature increasing rate was $10^{\circ} \mathrm{C} / \mathrm{min}$. The compositions of the effluents were analyzed by an on-line gas chromatograph (GC) analyzer in couple with a PE-Molsieve capillary column, using a thermal conductivity detector (TCD) for hydrogen analysis and a flame ionization detector (FID) for methane analysis.

\section{Results and Discussion}

\subsection{Structure of Ni/MCM-41 Catalysts}

The crystalline structures and phases of the Ni/MCM-41 catalysts were analyzed by XRD technique. As shown in Figure 1, several XRD peaks at $44.5^{\circ}, 51.5^{\circ}, 76.3^{\circ}$ and $92.7^{\circ}$ corresponding to metallic $\mathrm{Ni}$ in the catalysts are observed. The peak becomes sharper as the Ni loading increases from $10 \mathrm{wt} \%$ to $20 \mathrm{wt} \%$ and $30 \mathrm{wt} \%$, indicating that the diameter of $\mathrm{Ni}$ particle is larger at higher $\mathrm{Ni}$ loading.

The morphological features of the Ni/MCM-41 solids were studied by TEM. Figure 2 shows the TEM micrographs of the $30 \% \mathrm{Ni} / \mathrm{MCM}-41$ solid calcined at $600^{\circ} \mathrm{C}$. 


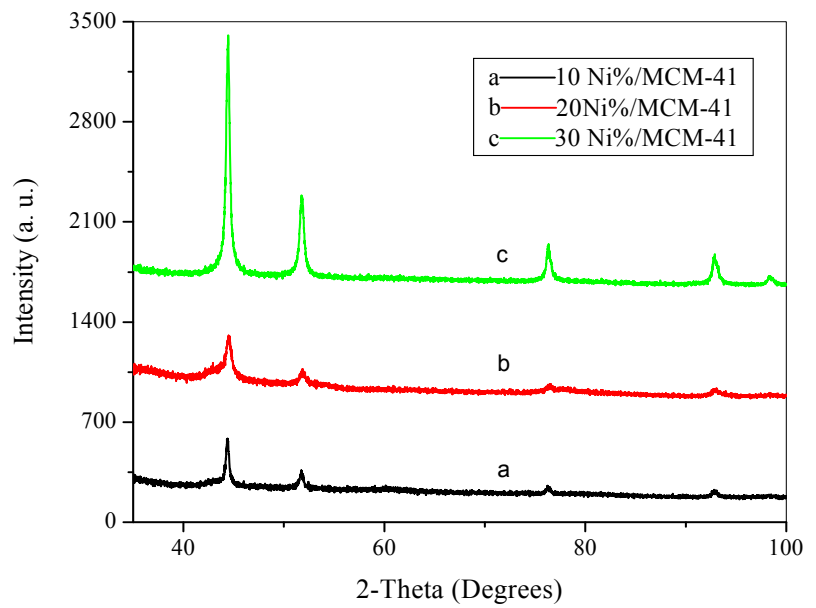

Figure 1. XRD patterns of the catalysts with different Ni content.

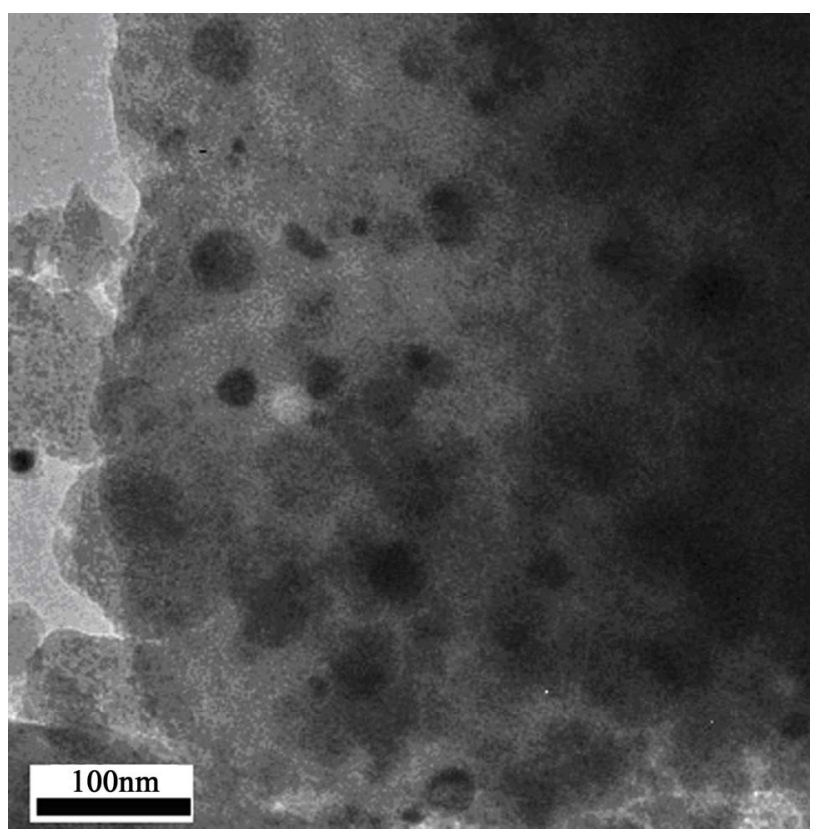

Figure 2. A TEM micrograph of a $30 \% \mathrm{Ni} / \mathrm{MCM}-41$ catalyst.

In this catalyst, many Ni particles with a shape as pseudo-sphere are observed. The distribution of Ni particle size is not homogeneous, ranging from $10 \mathrm{~nm}$ to $50 \mathrm{~nm}$ with an average diameter approximately $35 \mathrm{~nm}$. Because the Ni particles were loaded on the catalyst by using an impregnation method, it was difficult to control the $\mathrm{Ni}$ particle size distribution; however, the uneven distribution of the Ni particle size allowed us to investigate the effect of Ni particle size on the formation of carbon nanotubes during the reaction.

\subsection{Catalytic Evaluation}

Methane conversion over the $\mathrm{Ni} / \mathrm{MCM} 41$ catalysts is shown in Figure 3. Over all the catalysts, methane conversion increases with the reaction temperature increas- ing; for example, as the reaction temperature increases from $400^{\circ} \mathrm{C}$ to $600^{\circ} \mathrm{C}$, the $\mathrm{CH}_{4}$ conversion over the 20 $\mathrm{wt} \% \mathrm{Ni} / \mathrm{MCM}-41$ catalyst enhances from approximately $30 \%$ to $42 \%$. It is seen that $550^{\circ} \mathrm{C}$ is the best reaction temperature. Higher reaction temperature may result in the Ni particles sintering, thus reducing the catalytic activity. In the following experiments, we fixed the reaction temperature at $550^{\circ} \mathrm{C}$.

In order to evaluate the catalytic stability of the catalysts, MCD reaction was also tested in a period of 500 $\min$ at $550^{\circ} \mathrm{C}$. The results are presented in Figure 4. These catalysts exhibit high stability in this period. The average methane conversion is around $31 \%$ for $10 \%$ $\mathrm{Ni} / \mathrm{MCM}-41,43.2 \%$ for $20 \% \mathrm{Ni} / \mathrm{MCM}-41$ and $45.9 \%$ for $30 \% \mathrm{Ni} / \mathrm{MCM}-41$, respectively. It is found that the methane conversion over the $10 \mathrm{wt} \% \mathrm{Ni} / \mathrm{MCM}-41$ catalyst slightly decreases after $330 \mathrm{~min}$ of reaction, an approximately $7 \%$ drop is achieved. This catalyst contains small Ni particles which can be easily encapsulated by carbon deposits in the reaction, leading to activity decrease.

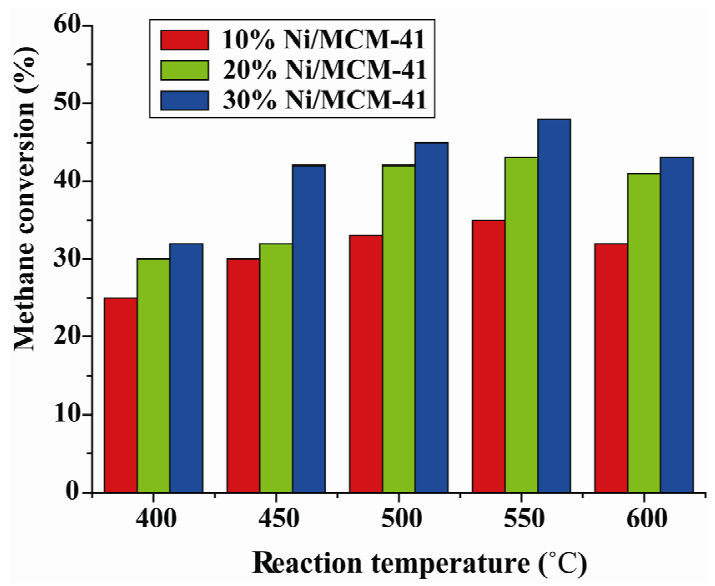

Figure 3. Methane conversion as a function of reaction temperature.

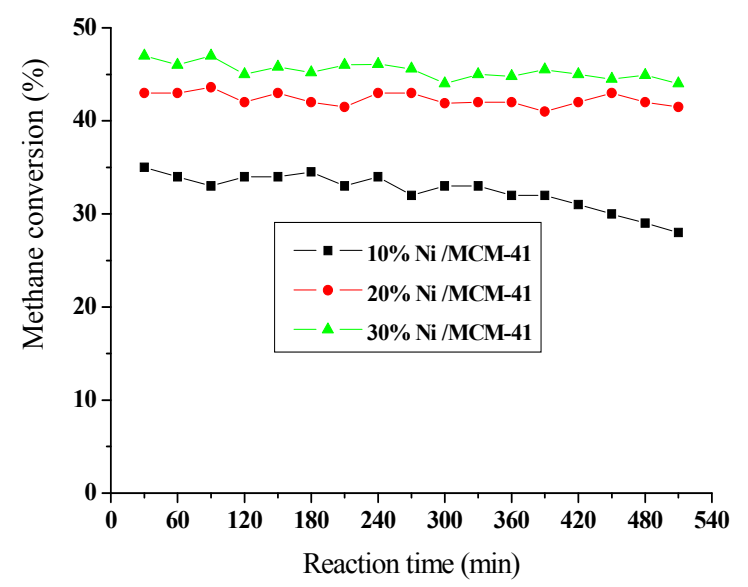

Figure 4. Methane conversion as a function of reaction time. 
During the reaction, both $\mathrm{CO}$ and $\mathrm{CO}_{2}$ were not detected. Therefore, hydrogen selectivity was $100 \%$. In 500 min of reaction, around $827 \mathrm{ml}, 1146 \mathrm{ml}$ and $1201 \mathrm{ml}$ of hydrogen were respectively produced on the catalysts with 10,20 and $30 \mathrm{wt} \%$ of Ni. The catalyst with higher $\mathrm{Ni}$ loading produces more hydrogen; this is related with more $\mathrm{Ni}$ active sites in the surface of the catalyst for methane decomposition.

\subsection{Carbon Nanotube Formation}

The formation of carbon nanotubes was studied by using Raman spectroscopy and electron transmission microscope. Figure 5 shows a Raman spectrum of the $30 \mathrm{wt} \%$ Ni/MCM-41 catalyst after 500 min of reaction. Two bands around $1576 \mathrm{~cm}^{-1}$ and $1325 \mathrm{~cm}^{-1}$ are observed. The peak around $1576 \mathrm{~cm}^{-1}$ corresponds to $\mathrm{G}$ band of the graphitic carbon arising from the $\mathrm{C}-\mathrm{C}$ stretching vibration; the peak around $1325 \mathrm{~cm}^{-1}$ is assigned to D band, corresponding to amorphous carbon or disorder structure and lattice defects in the microcrystalline carbon [12]. Raman spectrum indicates that two kinds of carbon were formed in the catalysts.

Figure 6 shows the TEM micrographs of the spent catalysts. Many CNTs with thick (multiwall) layers are clearly observed (Figure 6(a)). It is found that CNTs mainly grew with a tip-growth mode in which CNTs grow with Ni particle on its tip. This can be explained by the interaction degree between the $\mathrm{Ni}$ particles and the MCM-41 support [13]. In the present work, the $\mathrm{Ni}$ is introduced onto the surface of the support by impregnation, and therefore, Ni particles are mainly loaded on the surface but are not embedded or anchored inside the support, thus interaction between the Ni particles and the support is weak, which is in favour of the formation of carbon nanotube through the tip-growth mode, prevent the Ni particles from carbon encapsulation, and thus the

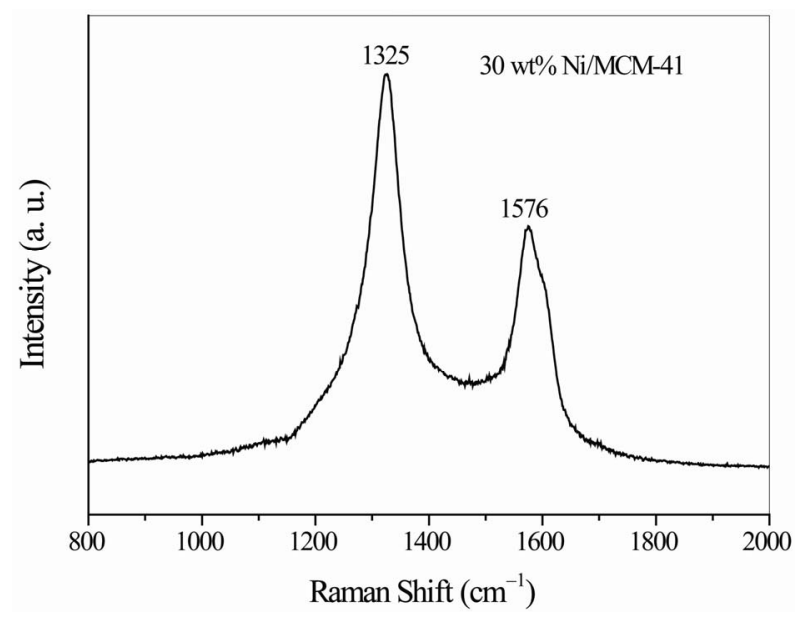

Figure 5. A Raman spectrum of $30 \% \mathrm{Ni} / \mathrm{MCM}-41$ spent catalyst after $500 \mathrm{~min}$ of reaction.

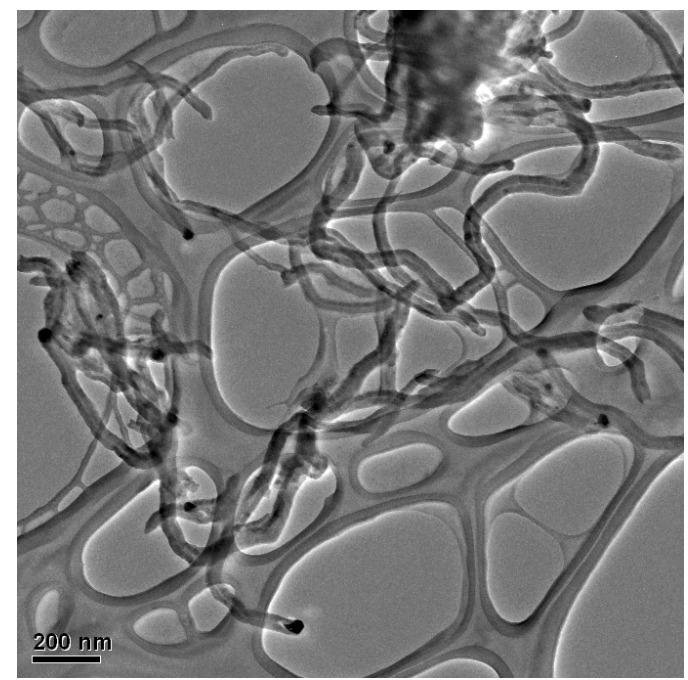

(a)

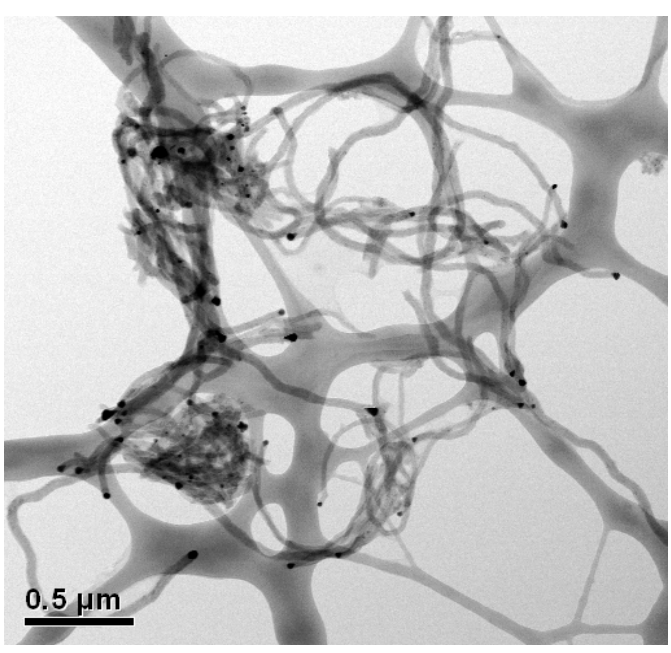

(b)

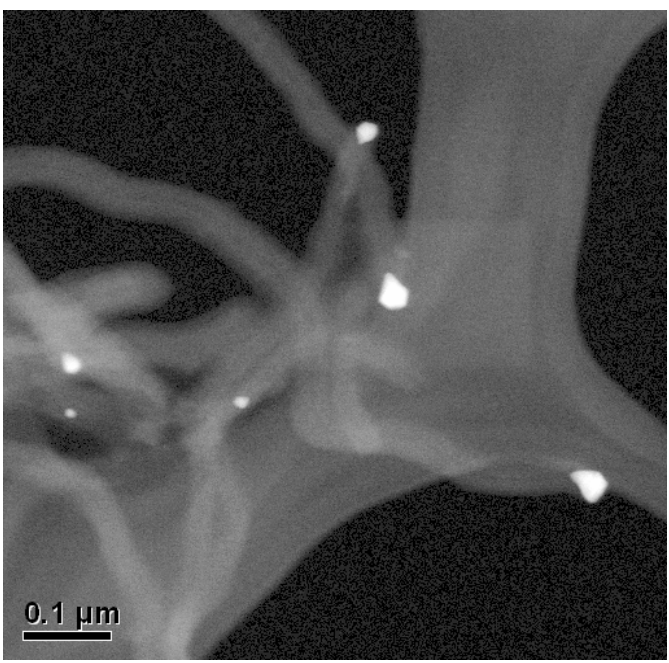

(c)

Figure 6. TEM micrographs of the $30 \mathrm{wt} \% \mathrm{Ni} / \mathrm{MCM}-41 \mathrm{ca}-$ talyst after $500 \mathrm{~min}$ reaction. 
catalyst remains a long lifetime. The diameter of CNTs has a close relation with the $\mathrm{Ni}$ particle size; large $\mathrm{Ni}$ particles lead to formation of CNTs with big diameter (Figure 6(b)). As a result, the inner diameter of the CNTs is largely determined by the diameter of the $\mathrm{Ni}$ particle. It is also observed that almost all of the CNTs, no matter whether they have thin or thick tube walls, are curved in certain degree (Figures 6(a) and (b)).

On the fresh Ni/MCM-41 catalysts, most of the Ni particles have a shape as pseudo-sphere (Figure 2). However, after the reaction, the Ni particle shows a shape diamond-like with a tail inserting into the carbon nanotube (Figure 6(c)). It is known that the melting point of metallic $\mathrm{Ni}$ is around $1452^{\circ} \mathrm{C}$, Ni particle may change its shape only at a temperature above its Tamman point $\mathrm{T}_{\mathrm{m}}$ $=726^{\circ} \mathrm{C}$. Under the present reaction condition, the reaction temperature is $550^{\circ} \mathrm{C}$. It seems impossible for $\mathrm{Ni}$ particle to alter its shape. It is reported that on a spent $\mathrm{Ni} / \mathrm{SiO}_{2}$ catalyst, $\mathrm{Ni}$ carbide $\left(\mathrm{Ni}_{3} \mathrm{C}\right)$ is formed [14]. $\mathrm{Ni}_{3} \mathrm{C}$ is unstable and it can be decomposed into nickel and graphitic carbon at a relative low temperature, i.e., $400^{\circ} \mathrm{C}$. It is also proven that carbon atoms produced from $\mathrm{CH}_{4}$ decomposition over the $\mathrm{Ni}$ based catalysts can form $\mathrm{Ni}_{\mathrm{x}} \mathrm{C}_{\mathrm{y}}$ solid solution as intermediate [15], at such condition, $\mathrm{C}$ atoms are able to move within the bulk of $\mathrm{Ni}$ particles and are then they are released from the $\mathrm{Ni}_{\mathrm{x}} \mathrm{C}_{\mathrm{y}}$ solid solution to form nanotubes at the interface of the Ni particle and support. Because methane decomposition is an exothermic reaction $(\Delta \mathrm{H}=75 \mathrm{~kJ} / \mathrm{mol})$, the temperature around $\mathrm{Ni}$ particle surface is, therefore, at somewhat overheat state, with respect to its surrounding temperature. As a result, the Ni-C system may transfer into a quasi-liquid state at a reaction temperature even lower than the Tamman temperature of $\mathrm{Ni}$; this provides the possibility for $\mathrm{Ni}$ changing its shape. It is also noted that a gradient of carbide concentration in the Ni particles during the reaction leads to pressure built up at the interface of $\mathrm{Ni}$ and support. When the graphitic layers are initially formed in parallel to the Ni crystal surface, carbon nanotube growth along the $\mathrm{Ni}$ crystal surface may drive the $\mathrm{Ni}$ particles to be squeezed out, changing $\mathrm{Ni}$ shape from pseudo-sphere to diamond-like.

\section{Conclusion}

The present work confirms that simultaneous production of hydrogen and CNTs can be realized in a single reaction of methane catalytic decomposition by using $\mathrm{Ni}$ / MCM-41 as catalyst. The Ni/MCM-41 catalysts exhibit high catalytic stability during $500 \mathrm{~min}$ of reaction. The formed CNTs have $20-50 \mathrm{~nm}$ in diameters and a few micrometers in length, depending on the reaction condition. Large Ni particles usually favour the formation of CNTs with big diameter. During the reaction, the shape of Ni particles changes from pseudo-sphere to diamond- like. All the CNTs consist of multiple layer walls and are curved in certain degree. The CNTs formation may grow with a tip-growth mode due to the weak interaction between $\mathrm{Ni}$ and MCM-41 support.

\section{Acknowledgements}

The authors would like to thank Mr. L. A. Moreno, Dr. J. Alberto Andraca Adame, and Dr. C. Angeles for their technical assistance.

\section{REFERENCES}

[1] L. Barretoa, A. Makihira and K. Riahi, "The Hydrogen Economy in the 21st Century: A Sutainable Development Scenario," International Journal of Hydrogen Energy, Vol. 28, No. 3, 2003, pp. 276-284.

[2] P. Tomczyk, "Fundamental Aspects of the Hydrogen Economy," World Futures: The Journal of Global Education, Vol. 65, No. 5-6, 2009, pp. 427-435. doi: $10.1080 / 02604020903021818$

[3] J. D. Holladay, "An Overview of Hydrogen Production Technologies," Catalysis Today, Vol. 139, No. 4, 2009, pp. 244-260. doi:10.1016/j.cattod.2008.08.039

[4] Y. Li, D. Li and D. Wang, "Methane Decomposition to $\mathrm{CO}_{\mathrm{x}}$-Free Hydrogen and Nano-Carbon Materials on Group 8-10 Base Metal Catalysts: A Review," Catalysis Today, Vol. 162, No. 1, 2011, pp. 1-46. doi:10.1016/j.cattod.2010.12.042

[5] K. P. De Jong and J. W. Geus "Carbon Nanofibers: Catalysis Synthesis and Applications," Catalysis Review: Science \& Technology, Vol. 42, No. 2, 2000, pp. 481-510.

[6] P. J. F. Harris, "Carbon Nanotubes and Related Structures: New Materials for the Twenty-First Century," Cambridge University Press, Cambridge, 2003.

[7] M. S. Rahammad, E. Croiset and R. R. Hudgins, "Catalytic Decomposition of Methane for Hydrogen Production," Topics in Catalysis, Vol. 37, No. 2-4, 2006, pp. 137-145. doi:10.1007/s11244-006-0015-8

[8] M. A. Ermakova, D. Y. Ermakov, A. L. Chuvilin and G. G. Kuvshinov, "Decomposition of Methane over Iron Catalysts at the Range of Moderate Temperatures: The Influence of Structure of the Catalytic Systems and the Reaction Conditions on the Yield of Carbon and Morphology of Carbon Filaments," Journal of Catalysis, Vol. 201, No. 2, 2001, pp. 183-197. doi:10.1006/jcat.2001.3243

[9] J. S. Beck, J. C. Vartuli, W. J. Roth, M. E. Leonowics, C. T. Kresge, K. D. Schmitt, C. T.-W. Chu, D. H. Olson, E. W. Sheppard, S. B. McCullen, J. B. Higgins and J. L. Schlenker, "A New Family of Mesopoous Molecular Sieves Prepared with Liquid Crystal Template," Journal of the American Chemical Society, Vol. 114, No. 27, 1992, pp. 10834-10843. doi:10.1006/jcat.2001.3243

[10] A. Sayari, M. Jaroniec and T. J. Pinnavaia, "Studies in Surface Science and Catalysis. Vol. 129: Nanoporous Materials II," Elsevier Science, Amsterdam, 2000.

[11] H. C. Liu, H. Wang, J. H. Shen, Y. Sun and Z. M. Liu, 
"Preparation, Characterization and Activities of NanoSized Ni/SBA-15 Catalyst for Producing COx-Free Hydrocarbon from Ammonia," Applied Catalysis A: General, Vol. 337, No. 2, 2008, pp. 138-147.

[12] A. Jorio, M. A. Pimenta, A. G. Souza Pilho, R. Satio, G. Dresselhaus and M. S. Dresselhaus, "Characterizing Carbon Nanotube Samples with Resonance Raman Scattering," New Journal of Physics, Vol. 5, No. 1, 2003, p. 139.

[13] E. Laouroux, P. Serp and P. Kalck, "Catalytic Routes toward Single Wall CNTs," Catalysis Review: Science \&
Technology, Vol. 49, No. 3, 2007, pp. 341-405.

[14] T. V. Choudhary, C. Sivadinarayana, C. C. Chusuei, A. Klinghoffer and D. W. Goodman "Hydrogen Production via Catalytic Decomposition of Methane," Journal of Catalysis, Vol. 199, No. 1, 2001, pp. 9-18. doi:10.1006/jcat.2000.3142

[15] P. L. Hansen, S. Helveg and A. K. Dayte, "Atomic-Scale Imaging of Supported Metals Nanocluster Catalysts in the Working State," Advanced Catalyst, Vol. 50, 2006, pp. 77-95. doi:10.1016/S0360-0564(06)50002-1 